\title{
AWARENESS OF BREAST CANCER AMONG TRIBAL WOMEN IN THE NILGIRIS DISTRICT
}

\author{
Kamalaveni and J. Santhiya \\ Department of Women's Studies, Bharathiar University, Coimbatore
}

\begin{abstract}
Breast cancer is the second leading cause of women in both developed and developing countries. A global burden of breast cancer is estimated to be 2 million by the year 2030 from developing countries according to Jermal A, 2011. The breast cancer incidence is growing in younger age and elder women population worldwide. In India, the breast cancer incidence is very high in rural women. Poverty, lack of education, shortage of screening facilities, advanced stages at diagnosis and gender inequality in healthcare activities etc.., are barriers for increasing the breast cancer incidence in India. This study was carried out to identify the level of knowledge to understand the awareness of breast cancer among tribal women in the Nilgiris District. The sample was collected from both married and unmarried women in the age group of 18-70 years. 40 women were randomly selected by using lottery method. A self administered questionnaire was used to collect the data. The data was analyzed through simple frequencies. The study results showed that the awareness regarding the breast cancer was relatively poor. However there is significant association between the age, marital life, education level, and the level of awareness.
\end{abstract}

Keywords: Breast cancer, awareness, Tribal women

\section{INTRODUCTION}

According to the study conducted by an international consortium of researchers, coordinated by the Institute for Health Metrics and Evaluation (IHME) at the University of Washington, the Breast cancer has replaced cervical cancer as the leading cause of cancer deaths among women in India. 'The Global Burden of Cancer 2013', published in the journal JAMA Oncology, that the breast cancer cases was jumped by 166 per cent. The GLOBOCON Report states that Breast cancer is the second leading cause of mortality and morbidity in both developed and developing countries, worldwide statistical report shows that an estimated 14.1 million new cancer cases and 8.2 million cancer related deaths in 2012(WHO). Breast cancer usually starts off in the inner lining of milk ducts or the lobules that supply them with milk. A malignant tumor can spread to other parts of the body. A breast cancer that started off in the lobules is known as lobular carcinoma, while one that developed from the ducts is called ductal carcinoma.

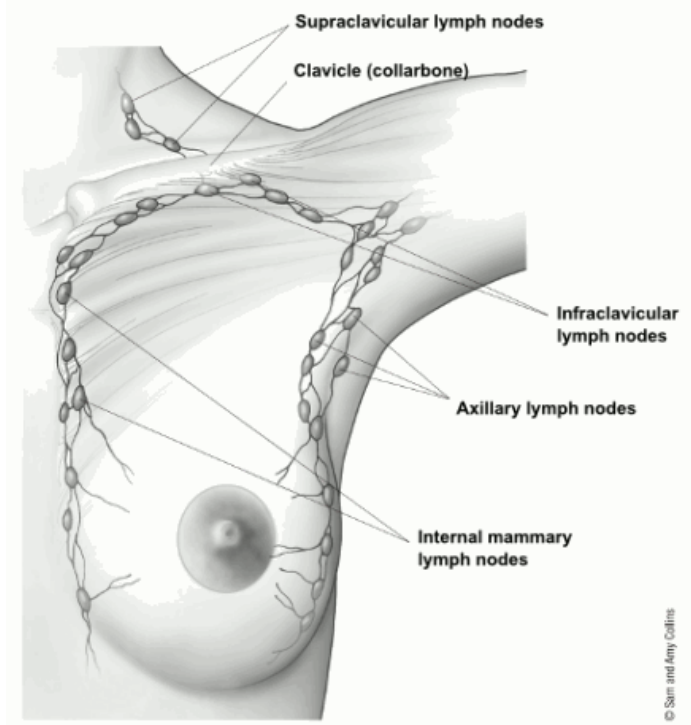

Lymph nodes in relation to the breast 


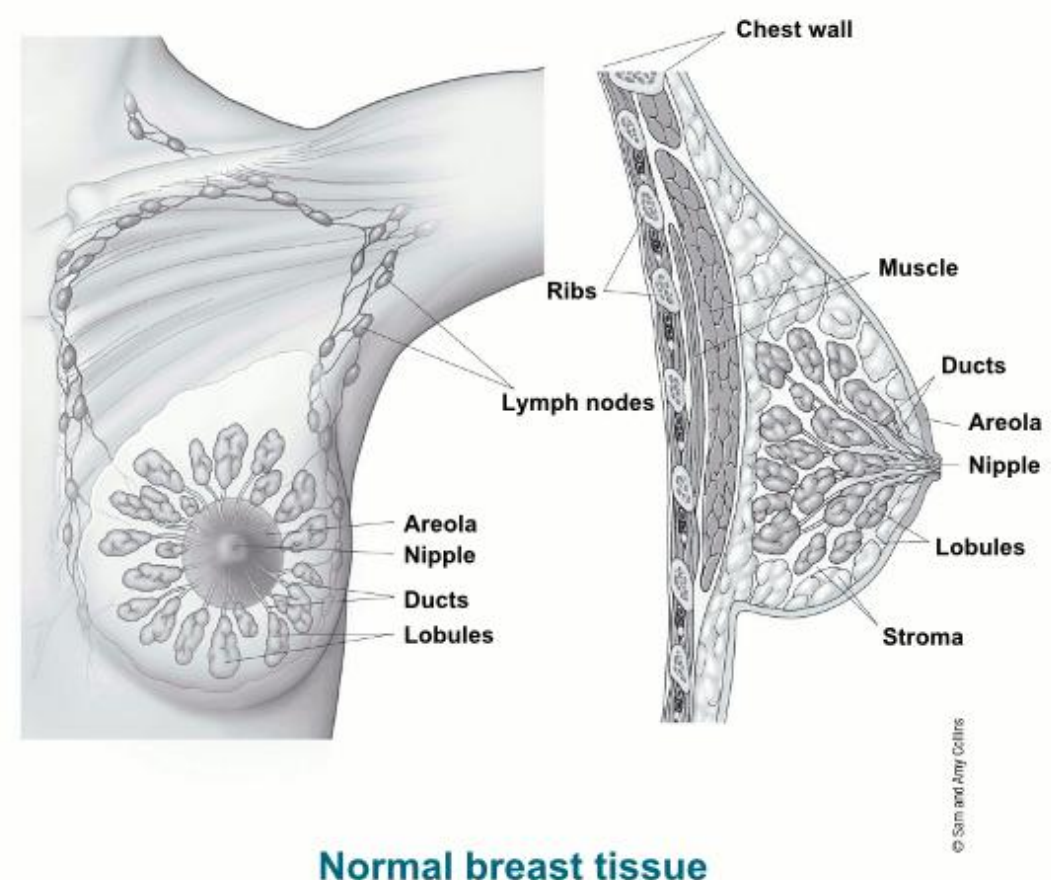

Source: American Cancer Society

Breast cancer is the most common cancer among women in India due to the different cultures, geographic variations, food habits and diets, etc., Breast cancer can be identified in early stages through the signs and symptoms. Most of the Indian studies showed that very few women knew about the symptoms regarding breast cancer. Breast cancer studies in South India results revealed that approximately $55 \%$ of women have never heard about breast cancer, $80-90 \%$ of respondents were not aware of symptoms and approximately $65 \%$ of respondents did not practice of self examination (Sri Devi, 2014; Kadam, 2014).

Breast Cancer is the Second leading cause of mortality and morbidity in both developed and developing countries. According to the International Agency for Research on Cancer (IARC) worldwide report an estimated 1671149 new breast cancer cases and 521907 deaths and 144937 new breast cancer incidence and 70218 deaths occurs in India. Mumbai is the highest breast cancer incidence in India as 5620 (30.3\%) cancer cases, 5354 (28.5\%) cancer incidence in Trivandrum and 3921 (22.4\%) cancer incidence in Chennai reported by the Hospital Based Cancer Registry 2007-2011 in India.
Breast cancer is a sensitive issue for women in the world. So, many of the women do not participate in screening tests. Lack of awareness about breast cancer and less availability of screening facilities is one of the reasons for delayed presentation of cancer diagnosis. An estimated 2700 mammograms installed in India, which represents less than $5 \%$ of that in the US and only $30 \%$ of advanced imaging technologies such as PET-CT cancer centers are available in India (EY, July 2015). Only one percentage of women had mammogram once in a year between the age group of 40 and 69 years in India as compared to $30 \%$ in China and 65\% in the US in 2014 (Poornasudha, 2013). The data was collected from 2009 to 2011, only $43 \%$ of Indian women were diagnosed at an early stage of breast cancer (i.e., Stage I or stage II) as compared to $62 \%$ in the US, $72 \%$ in China and $81 \%$ of breast cancers were diagnosed at an early stage in UK. As a result, mortality rates are increasing four to six times higher in India than the US and the cost of treatment to be higher than the annual household income for over $80-85 \%$ of households in India. (EY analysis, July 2015). 
Though the government had taken action in XII five year plan for implementing the availability of opportunistic screening services for cancer at the Sub-Center, primary and district level centers in all 664 districts, women use the services at lower level because of fear and embarrassment. According to the National Family Health Survey -4 reported that $14 \%, 16.9 \%$ of urban and rural women have ever undergone breast cancer examinations in Tamil Nadu and only $20.0 \%$ of women have ever undergone breast cancer examinations in The Nilgiris District (NFHS -4, 2015-16).

Tribal women are facing many health problems in India due to life style changes, changing food habits and diets etc..., Poverty, lack of education, cultural beliefs, shortage of screening facilities, advanced stages at diagnosis and gender inequality in healthcare activities etc.., are barriers for increasing the breast cancer incidence among women in India. The study aims to understand the level of awareness about breast cancer among tribal women in The Nilgiris District.

\section{OBJECTIVE}

To understand the level of awareness about breast cancer among tribal Women

\section{HYPOTHESIS}

- There is no association between age and breast cancer awareness of the respondents.

- There is no association between education and breast cancer awareness of the respondents

- There is no association between marital life and breast cancer awareness of the respondents.

\section{METHODOLOGY}

The study has used both primary and secondary data. Interview schedule was used to collect primary data. Secondary data have been collected form Text books, Journals and related Websites. Coonoor Panchayat union in The Nilgiris District was selected in this study. There are 6 panchayats included in this Union. Melur panchayat was randomly selected for the study. There are 192 female tribes living in this village. 40 samples were randomly selected by using lottery method. Interview schedule was used to collect the data from married and unmarried women. The data were analyzed by using SPSS Software Version 21. Descriptive statistics were used to analyze the results.

\section{RESULTS}

$40 \%$ of women were in the age group of 36-53 years, $32.5 \%$ of women had secondary level education, $65 \%$ of women are unemployed, and $70 \%$ of women belongs to Hindu community, $77.5 \%$ of women preferred living in nuclear family and $35 \%$ respondent's family income was between 10001 to15000 rupees. $65 \%$ of women have heard about breast cancer, $55 \%$ of women said breast cancer has to be detected early with increased the chances of survival rate, and $77.5 \%$ of women knew about breast cancer through media. Nearly half of the women knew about breast cancer symptoms and more than half of the women were unaware about breast cancer risk factors. $50 \%$ and $45 \%$ of women knew that low level of breast feeding (less than $1_{1 / 2}$ years) and family history of breast cancer can increase the risk for getting breast cancer. Nearly one third of women know about the breast cancer screening practices and very few percentages of women practiced the early detection practices. 
Table: 1

\begin{tabular}{|l|l|l|l|l|}
\hline & Variables & $\begin{array}{l}\text { Chi - Square } \\
\text { test }\end{array}$ & Sig & Null Hypothesis \\
\hline \multirow{2}{*}{$\begin{array}{l}\text { Awareness of } \\
\text { breast cancer }\end{array}$} & Age & .244 & Not Significant & Accepted \\
\cline { 2 - 5 } & Education & .004 & Significant & Rejected \\
\cline { 2 - 5 } & Marital Status & .002 & Significant & Rejected \\
\hline
\end{tabular}

Chi square test was applied to find the association between the age, education and marital status and breast cancer awareness of the respondents. The age of the respondent did not influence the breast cancer awareness level of the respondents. Therefore it is found that there is no significant association between them. So the null hypothesis is accepted. Chi square test was applied to find the association between the marital status and breast cancer awareness level of the respondents and it was found that there is significant association between them. Thus the hypothesis is rejected.

The statistics applied to find out the association between education and breast cancer awareness level of the respondents revealed that there is relationship between the educational status and breast cancer awareness level of the respondents which is substantiated with $99 \%$ significant. Hence the hypothesis is rejected.

$25 \%$ of women have low level, $50 \%$ of women have moderate level and $25 \%$ of women have high level of awareness about breast cancer in the selected tribal areas.

\section{DISCUSSION}

In developing countries like India, diagnostic facilities are too costly which hinders the normal public women to ignore the screening practices. The resource crisis and cultural stigma also plays a major role in ignoring the health issues. The finding of the study describes a wide gap in the level of awareness about breast cancer and its risk factors among tribal women of the Nilgiris district. Though majority of the tribal had heard about breast cancer, only half of them were aware of the basic symptoms of breast cancer. This indicates that regardless of massive efforts done in creating awareness on breast cancer at national and international level, the level of awareness of breast cancer has not reached at the community level. The burden of not reaching the community is due to the poor or unproductive education. Here the globalization and environmental degradation has played a role on tribal women's health.

Talking about the facts on breast cancer, Dr Vivek Gupta, Sr. Consultant- Surgical Oncology, informed that it was estimated that there would be $1,55,000$ new cases of breast cancer in the year 2015. About 76000 women in India were expected to die due to the disease. If we did not work on creating awareness about early detection of cancer, the figure could be much worse. Breast self examination and mammography were the noble technique to deduct breast cancer cases at early stages. Dr Rudra Acharya, Sr Consultant- Surgical Oncology, pointed out that ironically most of the cases in our country are diagnosed very late and according to the statistics of World Health Organisation, more than $60 \%$ of the women were diagnosed with breast cancer at stage III or IV in India. This drastically affected the survival rate and treatment options for the patients which substantiates the present study.

Though numerous campaigns on early detection of breast cancer practices are being organized locally and nationally by the Government, women still demonstrates moderate level of awareness regarding breast cancer. The present study highlights the demand for increasing the awareness level and wide range of cancer screening activities that is consistence with local beliefs in the community. The educational efforts should be designed exclusively to influence the variables that are related to conformity with early breast cancer detection behaviors. The cancer prevention program should highlight the provision of factual information about cancer and cancer screening practices in the context of a journeying of inaccurate beliefs about cancer that may restrain health behaviors. Self examination on breast cancer 
screening practices must be reinforced and they must be educated to practice on regular exercise pattern. Most of the tribal women did not take care of their health due to poverty and lack of education. Having effective relationship between family members should be allowed and encouraged to balance the breast cancer awareness level of the tribal women. The results showed that half of the women got their moderate awareness about breast cancer. According to the National Breast Cancer Foundation, Breast cancer affects one in eight women, and it is estimated that about 220,000 women are diagnosed each year,. Appreciatively, early diagnosis and treatment most often leads to a full recovery. Breast Cancer Awareness Month (October) is an annual campaign to raise awareness of the disease and the critical importance of testing for early detection.

\section{REFERENCE}

GLOBOCON 2012: An Estimated Cancer Incidence, Mortality and Prevalence Worldwide in 2012; International Agency for Research on Cancer, WHO

“XII Plan Document (2012-207)", Department of Health Research Website www.icmr.nic.in/publications/plan/ICMR XII plan (201217). pdf, accessed 1 June 2015.

Hospital Based Cancer Registry 2007-2011 in India

Call for Action: Expanding Cancer Care in India, July, 2015, EY Building a Better Working World, Emst \& Young LLP, Published in India.

National Family Health Survey - 4, 2015-16

Poornasudha Cancer Foundation, 2013, "Poornasudha \& Rotary International Breast Cancer on Wheels - An Affordable, Accessible option for Women of Karnataka"

Shimona Kanwar April 28, 2015, Times of India

The New Indian Express May 29, 2015. 